\title{
BMJ Open Frequency of exercise-induced ST-T- segment deviations and cardiac arrhythmias in recreational endurance athletes during a marathon race: results of the prospective observational Berlin Beat of Running study
}

Juliane Herm, ${ }^{1,2}$ Agnieszka Töpper, ${ }^{3,4,5}$ Alexander Wutzler, ${ }^{5}$ Claudia Kunze, ${ }^{2}$ Matthias Krüll,, ${ }^{6,7}$ Lars Brechtel,, ${ }^{6,7,8}$ Jürgen Lock, ${ }^{6,7,8}$ Jochen B Fiebach, ${ }^{2}$ Peter U Heuschmann, ${ }^{9,10}$ Wilhelm Haverkamp, ${ }^{5}$ Matthias Endres, ${ }^{1,2,11,12,13}$ Gerhard Jan Jungehulsing, ${ }^{2,14}$ Karl Georg Haeusler ${ }^{1,2}$

To cite: Herm J, Töpper A, Wutzler A, et al. Frequency of exercise-induced ST-Tsegment deviations and cardiac arrhythmias in recreational endurance athletes during a marathon race: results of the prospective observational Berlin Beat of Running study. BMJ Open 2017;7:e015798. doi:10.1136/ bmjopen-2016-015798

- Prepublication history and additional material are available. To view these files please visit the journal online (http://dx.doi. org/10.1136/bmjopen-2016015798).

GJJ and KGH contributed equally.

Received 30 December 2016 Revised 26 May 2017 Accepted 6 June 2017

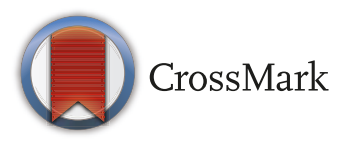

For numbered affiliations see end of article.

Correspondence to Dr. Karl Georg Haeusler; georg.häusler@charite.de

\section{ABSTRACT}

Objectives While regular physical exercise has many health benefits, strenuous physical exercise may have a negative impact on cardiac function. The 'Berlin Beat of Running' study focused on feasibility and diagnostic value of continuous ECG monitoring in recreational endurance athletes during a marathon race. We hypothesised that cardiac arrhythmias and especially atrial fibrillation are frequently found in a cohort of recreational endurance athletes. The main secondary hypothesis was that pathological laboratory findings in these athletes are (in part) associated with cardiac arrhythmias.

Design Prospective observational cohort study including healthy volunteers.

Setting and participants One hundred and nine experienced marathon runners wore a portable ECG recorder during a marathon race in Berlin, Germany. Athletes underwent blood tests 2-3 days prior, directly after and 1-2 days after the race.

Results Overall, 108 athletes (median 48 years (IQR 45-53), 24\% women) completed the marathon in $249 \pm 43 \mathrm{~min}$. Blinded ECG analysis revealed abnormal findings during the marathon in $18(16.8 \%)$ athletes. Ten $(9.3 \%)$ athletes had at least one episode of non-sustained ventricular tachycardia, one of whom had atrial fibrillation; eight $(7.5 \%)$ individuals showed transient ST-T-segment deviations. Abnormal ECG findings were associated with advanced age (OR 1.11 per year, $95 \% \mathrm{Cl} 1.01$ to 1.23 ), while sex and cardiovascular risk profile had no impact. Directly after the race, high-sensitive troponin $\mathrm{T}$ was elevated in $18(16.7 \%)$ athletes and associated with ST-Tsegment deviation (OR 9.9, 95\% Cl 1.9 to 51.5), while age, sex and cardiovascular risk profile had no impact. Conclusions ECG monitoring during a marathon is feasible. Abnormal ECG findings were present in every sixth athlete. Exercise-induced transient ST-T-segment deviations were associated with elevated high-sensitive troponin $\mathrm{T}(\mathrm{hsTnT})$ values.
Strengths and limitations of this study

- This is so far the largest study demonstrating feasibility of non-invasive ECG recording during a marathon race.

- More than 100 experienced marathon runners underwent a unique serial blood sampling within 2-3 days before the marathon, directly after crossing the finish line and 1-2 days after the marathon race.

- Cardiac MRI was performed in a subset of athletes with abnormal ECG findings and/or elevated troponin T values.

- Serial echocardiography and a standardised exercise capacity testing would have allowed for a more comprehensive interpretation of the results.

Trial registration ClinicalTrials.gov NCT01428778; Results.

\section{INTRODUCTION}

Regular physical exercise has many health benefits: improving blood pressure control, insulin sensitivity and lipid profiles; it reduces overall mortality and disability ${ }^{1}$ and the number of cardiovascular events. ${ }^{2}{ }^{3}$ Moreover, regular physical exercise also reduces the risk of certain cancers ${ }^{4}$ and the number of mood disorders. ${ }^{5}$ However, highly strenuous physical exercise may have a negative impact on cardiovascular health. ${ }^{6}$ While marathon running has become a popular sport, cardiac arrest is rare but occurs in about 1:100000 marathon runners, most commonly in those with hypertrophic cardiomyopathy or atherosclerotic coronary disease. ${ }^{7}$ Available data 
on incidence of myocardial infarction after running a marathon are limited to case reports ${ }^{8}$ and the prospective RACE Paris Registry, ${ }^{9}$ but elevated levels of troponin-a sensitive biomarker of cardiac injury-were reported in a relevant subset of asymptomatic marathon runners. ${ }^{10-12}$ Other potentially harmful effects of strenuous exercise, like right ventricular dysplasia and ventricular arrhythmia, have also been reported for triathletes and other ultra-endurance athletes. ${ }^{13-15}$ Moreover, a meta-analysis of mostly retrospective and small casecontrol series as well as a recent cohort study indicated that intense endurance sport increases the long-term risk of atrial fibrillation (AF). ${ }^{16} 17$ The European Heart Rhythm Association (EHRA) consortium has recently updated its recommendations regarding abnormal ventricular arrhythmias in endurance athletes and stated that a non-sustained ventricular tachycardia (nsVT) requires diagnostic evaluation for latent hypertrophic cardiomyopathy or ischaemic heart disease, especially if these occur under physical exercise ${ }^{18}$ However, there are so far very few publications regarding cardiac arrhythmias occurring during endurance sport. ${ }^{19-22}$

Herewith, we report the results of the prospective observational 'Berlin Beat of Running' study, ${ }^{23}$ demonstrating feasibility of continuous ECG monitoring in 108 recreational endurance athletes during a marathon race. The pre-defined primary aim of the study was to analyse the frequency of cardiac arrhythmias and especially $\mathrm{AF}$ in a cohort of recreational endurance athletes. Pre-defined secondary aims were as follows: (1) to assess risk factors associated with cardiac arrhythmias in marathon runners, (2) to analyse the association between laboratory findings and the presence of cardiac arrhythmias during the race, and (3) to investigate whether marathon runners with elevated troponin levels (after the race) have MRI-detected myocardial scars suggestive of previous myocardial infarction.

\section{METHODS}

\section{Study design}

The Berlin Beat of Running study is a prospective, observational, investigator-initiated cohort study. The study design has been published in detail. ${ }^{23}$ In short, all pre-registered participants were informed by the organisers of the marathon about the study, and they contacted the study personnel if they were interested. Participants aged 35-60 years with at least two marathon runs within the last 5 years and an average training of $40 \mathrm{~km}$ running per week were enrolled after giving written informed consent. Exclusion criteria included known cardiac disease or arrhythmia, prior stroke, tumour or infectious disease, severe liver or kidney disease, hyperthyroidism, pregnancy or lactation. Continuous ECG recording (using the CardioMem CM 4000 provided by GETEMED AG, Teltow, Germany) was started in 109 study participants up to 74 hours before the 38th BMW Berlin Marathon and continued throughout the entire race and for up to 58 hours afterwards. Laboratory assessment including high-sensitive troponin $\mathrm{T}$ (hsTnT) measurement with chemiluminescence immunoassays (Roche Diagnostics, Mannheim, Germany; cut-off $12 \mu \mathrm{g} / \mathrm{L}$ ) was performed up to 74 hours before, within $30 \mathrm{~min}$ post-race and for up to 58 hours after the race. The study protocol is in accordance with the Helsinki declaration and was approved by the ethics committee of the CharitéUniversitätsmedizin Berlin (EA4/042/11). The primary hypothesis was cardiac arrhythmias and especially $\mathrm{AF}$ are frequently found in experienced marathon runners. Therefore, the primary outcome is the number of marathon runners with newly diagnosed cardiac arrhythmias. The main secondary hypotheses were as follows: (1) there are predictable risk factors associated with cardiac arrhythmias in marathon runners, (2) pathological laboratory findings are (in part) associated with cardiac arrhythmias and (3) marathon runners with elevated troponin levels do not have MRI-detected myocardial scars suggestive of myocardial infarction. Follow-up information on medical history was assessed 1 year after the marathon.

\section{MRI analysis}

A cardiac MRI after the race was offered to all study participants with either ST-T-segment deviation or hsTnT elevation. 3T MRI (Magnetom Tim Trio; Siemens AG) was performed using a phased array receiver coil during breath-holds gated to the electrocardiogram (Body Matrix-coil \#TATS; Siemens AG). Cine images of 3 long-axis and 14-18 short-axis views (slices of $4 \mathrm{~mm}$ ) were created using a steady-state free precision technique. ${ }^{24}$ Eight minutes after intravenous administration of 10-12 mL Gadovist (Bayer Schering Pharma AG) at a concentration of $1 \mathrm{mmol} / \mathrm{mL}$, these views were repeated using a short inversion recovery sequence and continuously adjusting the inversion time. ${ }^{25}$

\section{ECG analysis}

ECG monitoring was performed using a two-channel portable ECG recorder (CardioMem CM 4000; GETEMED $\mathrm{AG})$. The cardiologists (AT, AW and $\mathrm{WH}$ ) who analysed the ECG data were blinded for demographic, clinical or laboratory data. The five recorded leads were placed as follows in order to obtain two independent bipolar channels: left (1) and right (2) on the first intercostal space, right on the sixth intercostal space parasternal (3) and mid-clavicular line (4), and left ninth intercostal space mid-clavicular line (5). As there are no published recommendations on interpretation of a Holter ECG in athletes, we followed recommendations available for interpreting a 12-lead ECG in athletes ${ }^{26}$ as well as recent EHRA guidelines on ventricular arrhythmias. ${ }^{18}$ In line with this, we defined an abnormal ECG as presence of ST-T-segment deviation under physical exercise or arrhythmias. Low-pass filtering was set at $0.05 \mathrm{~Hz}$ in order to detect changes in the ST-T-segment. The ST segment was considered abnormal in the virtually artefact-free two-lead ECG if horizontal or down-sloping $\geq 1 \mathrm{~mm}$ occurred over the $60 \mathrm{~ms}$ after the J-junction $(80 \mathrm{~ms}$ if the 
heart rate was $<120$ beats per minute) ${ }^{27}$ ST-segments were analysed in relation to the TP segment. Segments were analysed after recording of stable isoelectric TP segments in three consecutive beats. If single QRS complexes showed notching, slurring or fragmentation, QRS and ST intervals were excluded from further analysis. Episodes lasting more than $30 \mathrm{~s}$ preceded and followed by regular ECG recording were also considered abnormal. Drezner et al defined atrial arrhythmias as atrioventricular (AV) block grade IIb or III, AF or supraventricular tachycardia (SVT) ${ }^{26}$ Ventricular arrhythmias were defined as nsVT of at least three premature ventricular complexes (PVCs) and a heart rate of $\geq 100$ beats per minute. ${ }^{1826}$

\section{Statistical analysis}

In accordance with the sample size calculation, we planned to include 110 participants into the study. ${ }^{23}$ For categorical data, absolute and relative frequencies were calculated using SPSS Statistics V.22. In the case of continuous variables with nearly normal distribution, we used the arithmetic mean, SD, minimal and maximal values, otherwise median, quartiles, and minimal and maximal values. The $\chi^{2}$ test was used to compare proportions for dichotomous outcomes between independent groups or to test independency of two dichotomous variables within a population. Outcomes in an ordinal scale or continuous outcomes were analysed using the t-test or the MannWhitney $\mathrm{U}$ test, depending on normality or non-normality of distribution. A $p$ value of $<0.05$ was considered to be statistically significant. In multivariate analysis, potential impact factors identified on a $\mathrm{p}<0.05$ level in univariate analysis were entered in a binary logistic regression model using backwards selection.

\section{RESULTS}

\section{Baseline data of study participants and feasibility of ECG recording}

Overall, 109 (99.1\%) of 110 study participants took part, and 108 (98.2\%) participants finished the 38th BMW Berlin Marathon 2011 in an average running time of $249 \pm 43 \mathrm{~min}$. September 25, 2011, was a sunny day in Berlin and temperatures reached a maximum of $22^{\circ} \mathrm{C}$. Data quality of long-term Holter ECG was sufficient to ensure assessment of arrhythmias and ST-T-segment deviations in 107 (98.2\%) athletes, although motion and perspiration artefacts were present in the majority of athletes. In one athlete's device, a technical error occurred. Consistently wearing the ECG recorder on the upper arm using a carrier bag, no athlete reported problems in this regard. No athlete stopped wearing the ECG device prematurely. Baseline characteristics of these 107 participants are depicted in table 1 . The median age of these 107 participants was 48 years; $23.9 \%$ were women. The cardiovascular risk profile was low. The participants had run a median of five marathon races within the last 5 years and a median of eight marathon races in total. Their average weekly running distance prior to the race
Table 1 Baseline characteristics of the 107 participants of the 'Berlin Beat of Running' study who finished the marathon and who had evaluable ECG data

\begin{tabular}{lc}
\hline Age, mean, years, median (IQR) & $48(45-53)$ \\
\hline Female gender, \% (n) & $24.3(26)$ \\
\hline Body mass index, kg/m², median (IQR) & $23.4(21.6-24.7)$ \\
\hline Hypertension, \% (n) & $8.4(9)$ \\
Diabetes mellitus, \% (n) & $0(0)$ \\
\hline Heart failure, \% (n) & $0(0)$ \\
Coronary artery disease, \% (n) & $0(0)$ \\
Hyperlipidaemia, \% (n) & $2.8(3)$ \\
Current smoking, \% (n) & $6.5(7)$ \\
\hline Medication at enrolment & $0.9(1)$ \\
\hline Antiplatelet, \% (n) & 0 \\
\hline Oral anticoagulant, \% (n) & $1.9(2)$ \\
\hline Beta-blocker, \% (n) & $1.9(2)$ \\
\hline Statin, \% (n) & $6.5(7)$ \\
\hline Antihypertensive, \% (n) & \\
\hline
\end{tabular}

was $40 \mathrm{~km}$ (IQR 30-50 km). In addition, athletes regularly went cycling $(44.9 \% ; n=48)$ or swimming $(18.7 \% ; n=20)$, respectively.

\section{Cardiac arrhythmias or ST-T-segment deviation during the marathon}

During the race, mean heart rate was $156.7 \pm 9.4$ beats per minute. Minimum and maximum median heart rate were 133 (IQR 120-142) and 172 (IQR 166-177) beats per minute, respectively. We observed nsVT in $10(9.4 \%)$ athletes (figure 1), 2 (20\%) of whom were women. In athletes with nsVTs, the median number of beats was 3 (IQR 3-5; range 3-9), median rate was 166 beats per minute (IQR 149-188; range 133-224) and median duration of the recorded nsVT was $1121 \mathrm{~ms}$ (IQR 919-1841; range 901-4400). We did not observe an AV block or an SVT. Persistent AF was found in one male patient $(0.9 \%)$. Filtering of the monitors allowed interpretation of ST-T wave changes in fashion similar to a standard ECG. Exercise-induced ST-T-segment deviations occurred in eight $(7.5 \%)$ study participants during the marathon race (figure 2 ), two (25\%) of whom were women. Characteristics of all athletes with ST-T-segment deviation are displayed in the online supplementary file 1 . Intensity of ST-T-segment deviation in terms of ST level was $-0.7 \mathrm{mV}$ (IQR -0.8 to -0.3 ; range -0.9 to -0.16 ). ECG monitoring was prolonged for up to 54 hours (median 28 hours) after the marathon race. ST-T-segment deviations were not found in any athlete with ST-T-segment deviation during the marathon. One of these eight athletes also had nsVT. While four $(3.7 \%)$ athletes reported palpitations during the marathon race, one had AF, one had a single nsVT (lasting nine beats) and another athlete had multiple supraventricular premature beats (62/hour). No athlete reported cardiac pain or dyspnoea. An abnormal ECG 


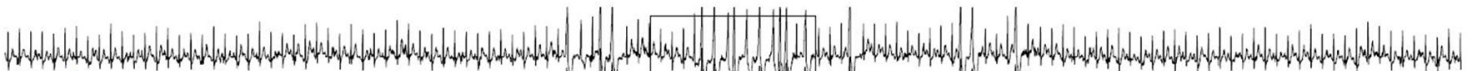

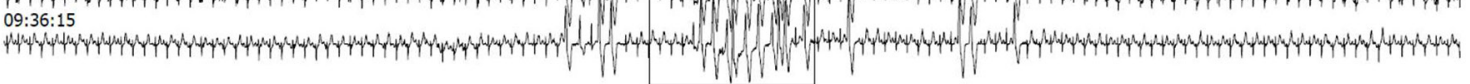

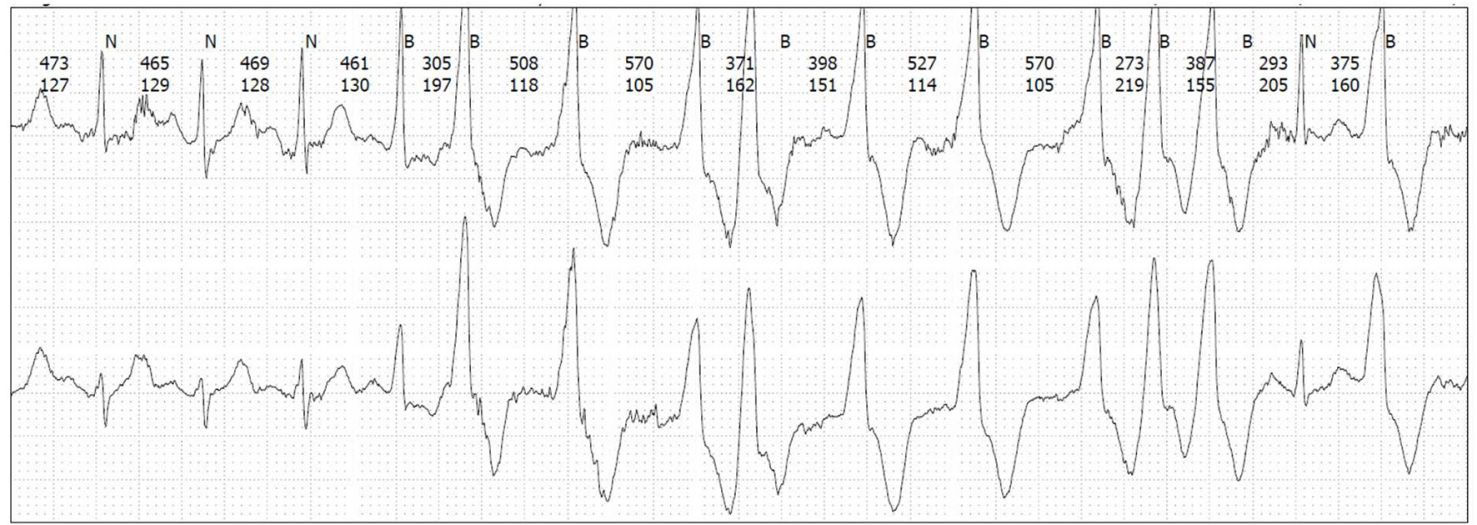

Figure 1 Non-sustained ventricular tachycardia in a well-trained 48-year-old male endurance runner without cardiovascular risk factors despite smoking.

according to pre-defined criteria was found in $16.8 \%$ $(\mathrm{n}=18)$ of all participants. In univariate analysis, advanced age $(\mathrm{p}=0.004)$ and a longer marathon finishing time $(\mathrm{p}=0.009)$ were associated with abnormal ECG findings, while sex, cardiovascular risk profile, haematocrit postrace and the number of previous marathons were not. In multivariate analysis, advanced age remained significant (OR 1.11 per year, 95\% CI 1.01 to 1.23) (table 2). In addition, athletes with an abnormal ECG had a higher frequency of PVCs (median 3.0 (IQR 1.0 to 12.3) vs 23.5 (IQR 10.0 to 44.0 ), $\mathrm{p}<0.001$ ) during the marathon race.

\section{Cardiac biomarkers and ECG changes during the marathon}

At baseline, hsTnT was normal in all marathon runners $(<50 \mathrm{ng} / \mathrm{L})$. Within minutes after the race was finished, hsTnT was elevated above $50 \mathrm{ng} / \mathrm{L}$ in $18(16.8 \%)$ participants and median hsTnT was $3 \mathrm{ng} / \mathrm{L}$ (IQR 2-4; range $1-22)$. Median hsTnT values in 18 athletes with elevated
hsTnT was $68.5 \mathrm{ng} / \mathrm{L}$ (IQR 62.8-85.5; range 50-216). Characteristics of all athletes with elevated hsTnT are displayed in the online supplementary file 1 . In all athletes, median creatine kinase (CK) and CK-MB were 130 U/L (IQR 103-176) and 20 U/L (IQR 17-24) pre-marathon, respectively. Post-marathon CK was 336 (IQR 252-417) U/L and CK-MB was 35 (IQR 29-41) U/L.

Comparing athletes with an elevated hsTnT post-marathon with those without, we found no difference in age, sex, cardiovascular risk factors, training level or post-marathon CK-MB values (table 3). In runners with elevated hsTnT, we found more frequent ST-T-segment deviations $(p<0.0001)$ but no association with cardiac arrhythmias. In addition, elevated hsTnT was found in individuals with a longer marathon finishing time $(p=0.040)$. Athletes with elevated hsTnT had a lower haematocrit compared with athletes without hsTnT elevation $(p=0.003)$. In

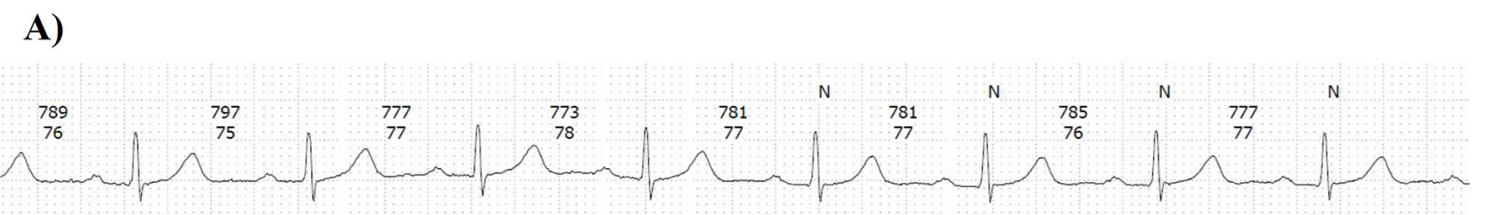

\section{B)}

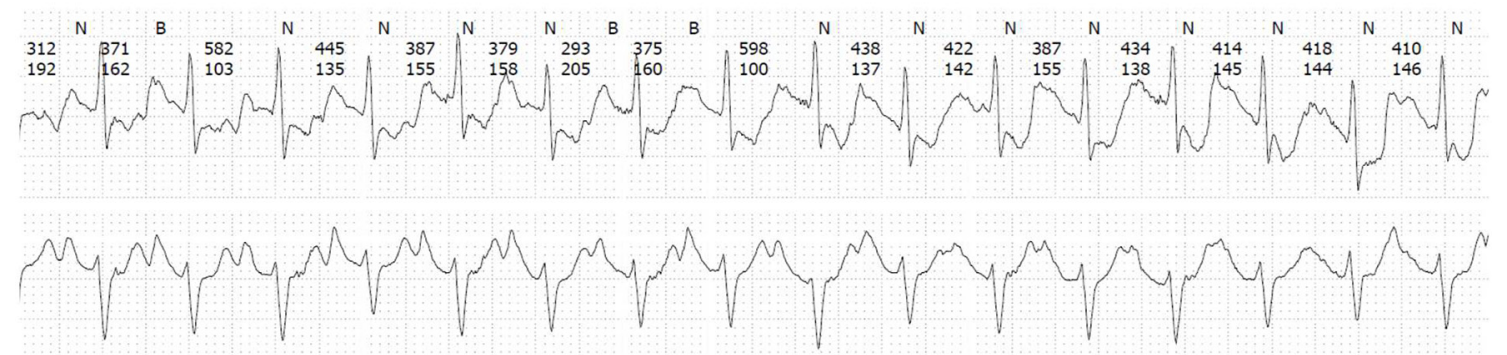

Figure 2 ECG at rest (A) and exercise-induced ST-segment deviations (B) in a 60-year-old male endurance runner without cardiovascular risk. 
Table 2 Cardiovascular risk profile and training status of recreational athletes with or without abnormal ECG findings, respectively

\begin{tabular}{|c|c|c|c|c|}
\hline & $\begin{array}{l}\text { Normal } \\
\text { ECG }\end{array}$ & Abnormal ECG & $\begin{array}{l}\text { Univariate } \\
\text { analysis }\end{array}$ & Multivariate analysis \\
\hline & $\mathrm{n}=89$ & $n=18$ & p Value* & OR $(95 \% \mathrm{Cl})$ \\
\hline Age, years, median (IQR) & $48(44-50)$ & $54(48-59)$ & 0.004 & 1.11 (1.01 to 1.23$)$ \\
\hline Female gender, \% (n) & $24.7(22)$ & $22.2(4)$ & 0.822 & \\
\hline \multicolumn{5}{|l|}{ Physical activity } \\
\hline Marathon runs $\leq 5$ years, median (IQR) & $5(4-10)$ & $6(4-7)$ & 0.923 & \\
\hline Marathon runs total, $n$, median (IQR) & $9(5-18)$ & $7(6-14)$ & 0.573 & \\
\hline Current running, km/week, median (IQR) & $65(50-80)$ & $58(50-70)$ & 0.151 & \\
\hline Regular running, km/week, median (IQR) & $40(30-50)$ & $40(30-50)$ & 0.409 & \\
\hline Present marathon time, min, median (IQR) & $238(215-268)$ & $275(229-326)$ & 0.009 & 1.44 (0.98 to 2.12$)$ \\
\hline Haematocrit post-race, \%, median (IQR) & $0.44(0.41-0.45)$ & $0.43(0.41-0.45)$ & 0.711 & \\
\hline Body mass index, $\mathrm{kg} / \mathrm{m}^{2}$, mean $\pm \mathrm{SD}$ & $23.2 \pm 2.2$ & $23.6 \pm 1.9$ & 0.449 & \\
\hline \multicolumn{5}{|l|}{ Comorbidities } \\
\hline Hypertension, \% (n) & $6.7(6)$ & $16.7(3)$ & 0.166 & \\
\hline Hyperlipidaemia, \% (n) & $2.2(2)$ & $2.8(3)$ & 0.438 & \\
\hline Current smoking, \% (n) & $5.6(5)$ & $11.1(2)$ & 0.390 & \\
\hline
\end{tabular}

ST-segment deviation, atrioventricular or ventricular arrhythmias (atrioventricular block grade IIb or III, triplets, non-sustained ventricular tachycardia, supraventricular tachycardia) or atrial fibrillation were regarded as abnormal findings. Values are expressed in \% ( $\mathrm{n}$ ), mean $\pm \mathrm{SD}$ or median (IQR) as appropriate. Multivariate analysis was calculated in a binary logistic regression model using backwards selection.

${ }^{*} \mathrm{p}$ Value calculated by $\chi^{2}$ test or Mann-Whitney $U$ test, as appropriate.

multivariate analysis, ST-T-segment deviation (OR 9.9, $95 \%$ CI 1.9 to 51.5 ) as well as haematocrit (OR $0.76 \%$, $95 \%$ CI 0.62 to 0.92$)$ remained statistically significant. Within 48 hours post-marathon, hsTnT was within normal range in $106(99.1 \%)$ athletes; one athlete with no substantial ECG alterations during the marathon showed a persisting hsTnT elevation but normal 12-lead ECG post-marathon. Follow-up information was available for all 8 athletes with ST-T-segment deviation and for 8 out of 10 patients with nsVT during the race. None of the athletes reported a cardiovascular event within 1 year after the race.

\section{Cardiac MRI in athletes with ST-T-segment deviation or elevated hsTnT}

Cardiac MRI was offered to all study participants with ST-T-segment deviation or hsTnT elevation. Five out of eight athletes with ST-T-segment deviation and hsTnT elevation as well as in 5 out of 18 athletes with hsTnT elevation but without ST-T-segment deviation underwent MRI within 10-42 days after the marathon race. Age, sex and cardiovascular risk factors did not differ in the 10 athletes undergoing cardiac MRI and the 14 athletes who did not undergo cardiac MRI. Cardiac MRI revealed no pathological findings for cardiac function, and there was no late gadolinium enhancement indicating myocardial fibrosis. Additional cardiac work-up was strongly recommended in all patients with pathological ECG findings.

\section{DISCUSSION}

This is so far the largest study demonstrating feasibility of ECG recording during a marathon race, which may help counselling a subset of endurance athletes regarding exercise-associated complications. One main finding of the Berlin Beat of Running study is the unexpectedly high rate of abnormal ECG findings in $17 \%$ of recreational endurance athletes. Moreover, this is the first study reporting an association of transient ST-T-segment abnormalities during a marathon with elevated hsTnT levels after finishing the race. However, we cannot be sure that the observed ST-T-segment deviations are definitively based on silent ischaemia.

So far, there is limited data on ECG abnormalities during vigorous exercise. ${ }^{28}$ Franco et al reported 'no arrhythmias' in 19 male athletes during a marathon, ${ }^{21}$ while Aagaard $e t$ al found 'no ventricular arrhythmias' but AF in $2(4 \%)$ of 49 male endurance runners during a $30-\mathrm{km}$ race. ${ }^{22}$ Luurila et al reported the presence of ventricular premature complexes in $33(89 \%)$ of 37 recreational athletes during a ski marathon as well as ST-T-segment deviations in three $(8 \%)$ of these middle-aged men. ${ }^{20}$ Most recently, Grabs $e t$ al used a one-lead wireless ECG and reported premature atrial contractions but no arrhythmias in 20 male runners during a marathon race. ${ }^{19}$ In our prospective study, 10 (9.4\%) out of 107 recreational endurance athletes had a non-sustained ventricular arrhythmia during the marathon and one $(0.9 \%)$ athlete had AF. In addition, ST-T-segment deviations (figure 2) were 
Table 3 Troponin T elevation post-marathon in the 107 athletes who finished the marathon race and who had evaluable ECG data

\begin{tabular}{|c|c|c|c|c|}
\hline & $\begin{array}{l}\text { Troponin T } \\
<50 \mathrm{ng} / \mathrm{L} \mathrm{n}=89\end{array}$ & $\begin{array}{l}\text { Troponin T } \\
\geq 50 \mathrm{ng} / \mathrm{L} \mathrm{n}=18\end{array}$ & $\begin{array}{l}\text { Univariate analysis } p \\
\text { Value }^{\star}\end{array}$ & $\begin{array}{l}\text { Multivariate } \\
\text { analysis OR }(95 \% \mathrm{Cl})\end{array}$ \\
\hline $\begin{array}{l}\text { Age, years, median } \\
\text { (IQR) }\end{array}$ & $48(45-52)$ & $49(45-53)$ & 0.605 & \\
\hline Female gender, \% (n) & $21.3(19)$ & $38.9(7)$ & 0.114 & \\
\hline $\begin{array}{l}\text { Body mass index, } \mathrm{kg} / \\
\mathrm{m}^{2}, \text { mean } \pm \mathrm{SD}\end{array}$ & $23(22-25)$ & $23(22-25)$ & 0.723 & \\
\hline $\begin{array}{l}\text { Present marathon time, } \\
\text { min, median (IQR) }\end{array}$ & 236 (217-269) & 268 (237-309) & 0.040 & 1.25 (0.83 to 1.87$)$ \\
\hline $\begin{array}{l}\text { Marathon runs } \leq 5 \text { years, } \\
n \text {, median (IQR) }\end{array}$ & $6(4-10)$ & $5(3-8)$ & 0.327 & \\
\hline $\begin{array}{l}\text { Marathon runs total, } n \text {, } \\
\text { median (IQR) }\end{array}$ & $9(6-18)$ & $7(5-12)$ & 0.147 & \\
\hline $\begin{array}{l}\text { Regular weekly running, } \\
\mathrm{km} \text {, median (IQR) }\end{array}$ & $40(30-50)$ & $40(30-50)$ & 0.791 & \\
\hline $\begin{array}{l}\text { Coexisting } \\
\text { hypertension, \% (n) }\end{array}$ & $9.0(8)$ & $5.6(1)$ & 0.632 & \\
\hline Hyperlipidaemia, \% (n) & $3.4(3)$ & $0(0)$ & 0.429 & \\
\hline $\begin{array}{l}\text { ST-T-segment deviation, } \\
\%(\mathrm{n})\end{array}$ & $3.4(3)$ & $27.8(5)$ & $<0.0001$ & 9.9 (1.90 to 51.5$)$ \\
\hline Arrhythmias, \% (n) & $11.2(10)$ & $5.6(1)$ & 0.469 & \\
\hline $\begin{array}{l}\text { Troponin pre-race, } \mu \mathrm{g} / \mathrm{L} \text {, } \\
\text { median (IQR) }\end{array}$ & $0.012(0.012-0.012)$ & $0.012(0.012-0.012)$ & 0.131 & \\
\hline $\begin{array}{l}\text { Creatinine pre-race, mg/ } \\
\mathrm{dL} \text {, median (IQR) }\end{array}$ & $0.86(0.81-0.96)$ & $0.85(0.77-0.97)$ & 0.761 & \\
\hline $\begin{array}{l}\text { Creatinine post-race, } \\
\mathrm{mg} / \mathrm{dL} \text {, median (IQR) }\end{array}$ & $1.27(1.11-1.46)$ & $1.34(1.17-1.48)$ & 0.424 & \\
\hline $\begin{array}{l}\text { CK post-race, U/L, } \\
\text { median (IQR) }\end{array}$ & $333(250-412)$ & $350(291-611)$ & 0.263 & \\
\hline $\begin{array}{l}\text { CK-MB post-race, U/L, } \\
\text { median (IQR) }\end{array}$ & 35 (28 to 41$)$ & 33 (29 to 52$)$ & 0.609 & \\
\hline $\begin{array}{l}\text { Haematocrit post-race, } \\
\% \text {, median (IQR) }\end{array}$ & $44(42-46)$ & $41(39-44)$ & 0.003 & 0.76 (0.62 to 0.92$)$ \\
\hline
\end{tabular}

Values are expressed in percent $(n)$, mean \pm SD or median (IQR) as appropriate. Multivariate analysis was calculated in a binary logistic regression model using backwards selection.

${ }^{*} \mathrm{p}$ Value calculated by $\chi^{2}$ test or Mann-Whitney $U$ test, as appropriate.

CK, creatine kinase.

detected in eight $(7.5 \%)$ athletes. Advanced age was associated with abnormal ECG findings (table 2). According to the haematocrit, low hydration-potentially impacting on cardiac preload-was not linked to abnormal ECG findings. However, analysing athletes with ST-T-segment deviations, AF or ventricular arrhythmias, the underlying mechanisms of these pathological conditions may differ and the results of the multivariate analysis do not apply to a single condition.

Despite the fact that increased levels of physical activity were associated with a lower relative risk of myocardial infarction, $4 \%$ of patients with myocardial infarction report having performed strenuous exercise within hours before the cardiovascular event. ${ }^{3}$ By using different cut-offs, transient elevations in the level of troponin $\mathrm{T}$ or troponin I have previously been reported in $18 \%-69 \%$ of marathon runners. ${ }^{10-12}{ }^{29}$ In the Berlin Beat of Running cohort, hsTnT was elevated in $18(17 \%)$ out of 107 athletes but normalised within 48 hours in 17 (94\%) athletes. Interestingly, elevation of hsTnT was not related to age, sex, training status, the cardiovascular risk profile or the presence of cardiac arrhythmias during the race, but was related to exercise-induced ST-T-segment deviation $(\mathrm{p}<0.0001)$ and inversely correlated with the haematocrit (measured immediately after the race).

Cardiac MRI is now the gold standard for detecting myocardial damage ${ }^{30}$ and myocardial oedema as well as decreased ventricular function after a marathon race. ${ }^{31} 32$ We were not able to demonstrate late gadolinium enhancement as an indicator of permanent myocardial fibrosis 
in 10 experienced recreational athletes with ST-T-segment deviation or detected cardiac arrhythmia. This is in line with a previous study reporting no late gadolinium enhancement in 20 recreational athletes within 48 hours after a marathon race. ${ }^{31}$ Interestingly, a transient cardiac oedema was reported in $17(85 \%)$ out of 20 marathon runners, ${ }^{31}$ but no correlation was reported between biomarkers and cardiac oedema. We are, however, unable to exclude a transient cardiac oedema in marathon runners because cardiac MRI was performed within 10-42 days after the marathon race.

Taken together, vigorous exercise can go along with transient troponin elevation, ST-T-segment alterations or nsVT in a fit and active population. However, athletes with ST-T-segment deviation or nsVT during the race did not report a cardiovascular event within 1 year afterwards. Thus, these findings are likely to be benign, but it was still recommended to rule out structural heart disease or obstructive coronary artery disease in these athletes. Our results strengthen the assumption that hsTnT elevation originates from the heart and not primarily from non-cardiac sources. ${ }^{8}$ However, we are unable to draw final conclusions. Whether borderline cardiac damage by repetitive strenuous exercise could lead to permanent (potentially arrhythmogenic) cardiac remodelling is under debate. ${ }^{633}$

Focusing primarily on the feasibility of portable ECG monitoring and detection of ECG changes during the race, major limitations of the observational 'Berlin Beat of Running' study are the missing (serial) echocardiography or cardiac stress MRI, thus limiting the clinical significance of the observed ST-T-segment changes and elevated hsTnT levels. Furthermore, a normal cardiac MRI within days after the race does not completely rule out (transient) exercise-induced cardiac damage. ${ }^{34}$ Since only one-fourth of all athletes were women and because of a potential selection bias during enrolment, the generalisability of our results is limited. Moreover, due to the limited number of endpoints observed, we believe that the results of the multivariate analysis should be interpreted with caution. Combining nsVT and ST-T-segment deviations for statistical analysis may have introduced an information bias. Unfortunately, it was impossible to assess the mean duration of ST-T-segment deviation in more detail, as ST-T-segment changes were present intermittently. Finally, exercise capacity testing would have allowed more accurate evaluation of training status.

\section{CONCLUSION}

ECG recording during a marathon race is feasible, which may be helpful in the diagnostic work-up of selected athletes. Cardiac arrhythmias or exercise-induced ST-T-segment deviations appear in a relevant subset of experienced recreational athletes during a marathon race and predominantly in older athletes. Marathon-induced ST-T-segment deviations were associated with elevated hsTnT values immediately after the race. Cardiac
MRI detected no myocardial fibrosis by late gadolinium enhancement in a subset of these athletes.

\section{Author affiliations}

${ }^{1}$ Department of Neurology, Charité-Universitätsmedizin Berlin, Berlin, Germany

${ }^{2}$ Center for Stroke Research Berlin, Charité-Universitätsmedizin Berlin, Berlin, Berlin, Germany

${ }^{3}$ Working Group on Cardiovascular Magnetic Resonance, Experimental and Clinical Research Center, Berlin, Germany

${ }^{4}$ Department of Cardiology and Nephrology, HELIOS Klinikum Berlin Buch, Berlin, Germany

${ }^{5}$ Department of Cardiology, Campus Virchow Klinikum, Charité-Universitätsmedizin Berlin, Berlin, Germany

${ }^{6}$ SMS Medical Institute Berlin GmbH, Berlin, Germany

${ }^{7}$ SCC EVENTS GmbH, Berlin, Germany

${ }^{8}$ Berlin Academy of Sports Medicine, Berlin, Germany

${ }^{9}$ Institute of Clinical Epidemiology and Biometry, University of Würzburg, Würzburg, Germany

${ }^{10}$ Clinical Trial Center Würzburg, University Hospital Würzburg, Würzburg, Germany

${ }^{11}$ German Center for Neurodegenerative Diseases (DZNE), Partner Site Berlin, Berlin, Germany

${ }^{12}$ German Center for Cardiovascular Diseases (DZHK), Partner Site Berlin, Berlin, Germany

${ }^{13}$ Berlin Institute of Health, Berlin, Germany

${ }^{14}$ Department of Neurology, Jüdisches Krankenhaus Berlin, Berlin, Germany

Acknowledgements The results of this study are presented clearly, honestly and without fabrication, falsification or inappropriate data manipulation, and we state that results of this study do not constitute endorsement by ACSM. We appreciate the work of the organising SCC EVENTS GmbH who supported the Berlin Beat of Running study in an outstanding manner. We would like to thank all members of the Berlin Beat of Running study team ${ }^{23}$ and all athletes for their participation. In addition, we thank Catherine Aubel (CSB) and Julia Herde (CSB) for critically reviewing the manuscript.

Contributors $\mathrm{JH}$ has made substantial contributions to acquisition, analysis and interpretation of data and drafted the manuscript. AT and AW have made substantial contributions to data analysis and interpretation of data. CK has made substantial contributions to design and acquisition of data. MK, LB, JL, JBF, WH and ME revised the manuscript critically for important intellectual content. PUH has made substantial contributions to analysis and interpretation of data and revised the manuscript critically for important intellectual content. GJJ has made substantial contributions to conception and design and revised the manuscript critically for important intellectual content. KGH has made substantial contributions to conception and design, analysis and interpretation of data and drafted the manuscript.

Funding The investigator-initiated "Berlin Beat of Running" study was supported by the SCC EVENTS GmbH, Berlin. Bayer Healthcare (Leverkusen, Germany) and Sanofi-Aventis Deutschland GmbH (Berlin, Germany) supported the study with an unrestricted grant. The GETEMED AG (Teltow, Germany) provided the ECG-recorders and comprehensive technical support. KGH, JH, CK, JBF, ME and GJJ received funding from the Federal Ministry of Education and Research via the grant Center for Stroke Research Berlin (01 E0 0801). ME received support from the Volkswagen-Stiftung, Deutsche Forschungsgemeinschaft and the EU.

Competing interests $\mathrm{JH}$ reports no conflict of interest. AT reports lecture fees from the Circle Institute. MK received consulting, lecture and advisory board fees from ALK, Berlin Chemie, Novartis, Mundipharma and Teva. LB reports research support from the German Ministry of Research and Education. JBF reports the following board memberships, consultancies and/or payments for lectures including service on speaker's bureaus: Boehringer Ingelheim, Lundbeck, BioClinica and Parexel. PUH reports research grants from the German Ministry of Research and Education, EU, Charité, Berlin Chamber of Physicians, German Parkinson Society, University Hospital Würzburg, Robert Koch Institute, Charité-Universitätsmedizin Berlin (within MonDAFIS; MonDAFIS is supported by an unrestricted research grant to the Charité from Bayer Healthcare), University Göttingen (within FINDAF randomized; FINDAF randomized is supported by an unrestricted research grant to the University Göttingen from Boehringer Ingelheim) and University Hospital Heidelberg (within RASUNOAprime; RASUNOAprime is supported by an unrestricted research grant to the University Hospital Heidelberg from Bayer Healthcare, BMS and Boehringer Ingelheim), outside submitted work. GJJ has received funding from 
the German Ministry for Education and Research. He has served on the Critical Event committees of the SourceXT registry and the ProTAVIC study (Edwards Lifesciences, USA). He serves as a consultant for Cipio Partners (Munich, Germany and Elron, Tel Aviv, Israel). He has received speakers' honoraria from Genzyme and Pfizer (20102013). ME and KGH report lecture fees and study grants from SanofiAventis and Bayer Healthcare.

Patient consent Obtained.

Ethics approval Ethics Commitee of the Charité-Universitaetsmedizin Berlin.

Provenance and peer review Not commissioned; externally peer reviewed.

Data sharing statement There are no additional data available for this study.

Open Access This is an Open Access article distributed in accordance with the Creative Commons Attribution Non Commercial (CC BY-NC 4.0) license, which permits others to distribute, remix, adapt, build upon this work non-commercially, and license their derivative works on different terms, provided the original work is properly cited and the use is non-commercial. See: http://creativecommons.org/ licenses/by-nc/4.0/

(c) Article author(s) (or their employer(s) unless otherwise stated in the text of the article) 2017. All rights reserved. No commercial use is permitted unless otherwise expressly granted.

\section{REFERENCES}

1. Chakravarty EF, Hubert HB, Lingala VB, et al. Reduced disability and mortality among aging runners: a 21-year longitudinal study. Arch Intern Med 2008;168:1638-46.

2. Soares-Miranda L, Siscovick DS, Psaty BM, et al. Physical activity and risk of coronary heart disease and stroke in older adults: the Cardiovascular Health Study. Circulation 2016;133:147-55.

3. Mittleman MA, Maclure M, Tofler GH, et al. Triggering of acute myocardial infarction by heavy physical exertion. Protection against triggering by regular exertion. Determinants of Myocardial Infarction Onset Study Investigators. N Engl J Med 1993;329:1677-83.

4. Winzer BM, Whiteman DC, Reeves MM, et al. Physical activity and cancer prevention: a systematic review of clinical trials. Cancer Causes Control 2011;22:811-26.

5. Carek PJ, Laibstain SE, Carek SM. Exercise for the treatment of depression and anxiety. Int J Psychiatry Med 2011;41:15-28.

6. La Gerche A, Heidbuchel H. Can intensive exercise harm the heart? You can get too much of a good thing. Circulation 2014;130:992-1002.

7. Kim JH, Malhotra R, Chiampas G, et al. Cardiac arrest during longdistance running races. N Engl J Med 2012;366:130-40.

8. Albano AJ, Thompson PD, Kapur NK. Acute coronary thrombosis in Boston marathon runners. N Engl J Med 2012;366:184-5.

9. Gerardin B, Collet JP, Mustafic H, et al. Registry on acute cardiovascular events during endurance running races: the prospective RACE Paris registry. Eur Heart J 2016;37:2531-41.

10. Eijsvogels TM, Hoogerwerf MD, Maessen MF, et al. Predictors of cardiac troponin release after a marathon. J Sci Med Sport 2015;18:88-92

11. Mehta R, Gaze D, Mohan S, et al. Post-exercise cardiac troponin release is related to exercise training history. Int $J$ Sports Med 2012;33:333-7.

12. Fortescue EB, Shin AY, Greenes DS, et al. Cardiac troponin increases among runners in the Boston Marathon. Ann Emerg Med 2007;49:137-43.

13. O'Keefe JH, Patil HR, Lavie CJ, et al. Potential adverse cardiovascular effects from excessive endurance exercise. Mayo Clin Proc 2012;87:587-95.
14. Heidbüchel H, Hoogsteen J, Fagard R, et al. High prevalence of right ventricular involvement in endurance athletes with ventricular arrhythmias. Role of an electrophysiologic study in risk stratification. Eur Heart J 2003;24:1473-80.

15. Harper RW, Mottram PM. Exercise-induced right ventricular dysplasia/cardiomyopathy-an emerging condition distinct from arrhythmogenic right ventricular dysplasia/cardiomyopathy. Heart Lung Circ 2009;18:233-5.

16. Abdulla J, Nielsen JR. Is the risk of atrial fibrillation higher in athletes than in the general population? A systematic review and metaanalysis. Europace 2009;11:1156-9.

17. Andersen K, Farahmand B, Ahlbom A, et al. Risk of arrhythmias in 52 755 long-distance cross-country skiers: a cohort study. Eur Heart $J$ 2013;34:3624-31.

18. Pedersen CT, Kay GN, Kalman J, et al. EHRA/HRS/APHRS expert consensus on ventricular arrhythmias. Europace 2014;16:1257-83.

19. Grabs V, Peres T, Zelger O, et al. Decreased prevalence of cardiac arrhythmias during and after vigorous and prolonged exercise in healthy male marathon runners. Am Heart J 2015;170:149-55.

20. Luurila OJ, Karjalainen J, Viitasalo M, et al. Arrhythmias and ST segment deviation during prolonged exhaustive exercise (ski marathon) in healthy middle-aged men. Eur Heart $J$ 1994;15:507-13.

21. Franco V, Callaway C, Salcido D, et al. Characterization of electrocardiogram changes throughout a marathon. Eur J Appl Physiol 2014;114:1725-35.

22. Aagaard $P$, Sahlén $A$, Bergfeldt $L$, et al. Heart rate and its variability in response to running-associations with troponin. Med Sci Sports Exerc 2014;46:1624-30.

23. Haeusler KG, Herm J, Kunze C, et al. Rate of cardiac arrhythmias and silent brain lesions in experienced marathon runners: rationale, design and baseline data of the Berlin Beat of Running study. BMC Cardiovasc Disord 2012;12:69.

24. Carr JC, Simonetti O, Bundy J, et al. Cine MR angiography of the heart with segmented true fast imaging with steady-state precession. Radiology 2001;219:828-34

25. Simonetti OP, Kim RJ, Fieno DS, et al. An improved MR imaging technique for the visualization of myocardial infarction. Radiology 2001;218:215-23.

26. Drezner JA, Ackerman MJ, Anderson J, et al. Electrocardiographic interpretation in athletes: the 'Seattle criteria'. Br J Sports Med 2013;47:122-4

27. Gramatikov B, lyer V. Intra-QRS spectral changes accompany ST segment changes during episodes of myocardial ischemia. $J$ Electrocardiol 2015;48:115-22.

28. Spethmann S, Prescher S, Dreger H, et al. Electrocardiographic monitoring during marathon running: a proof of feasibility for a new telemedical approach. Eur J Prev Cardiol 2014;21:32-7.

29. George K, Whyte G, Stephenson C, et al. Postexercise left ventricula function and cTnT in recreational marathon runners. Med Sci Sports Exerc 2004;36:1709-15.

30. Utomi V, Oxborough D, Whyte GP, et al. Systematic review and metaanalysis of training mode, imaging modality and body size influences on the morphology and function of the male athlete's heart. Heart 2013;99:1727-33.

31. Gaudreault V, Tizon-Marcos H, Poirier P, et al. Transient myocardial tissue and function changes during a marathon in less fit marathon runners. Can J Cardiol 2013;29:1269-76.

32. Karlstedt E, Chelvanathan A, Da Silva M, et al. The impact of repeated marathon running on cardiovascular function in the aging population. J Cardiovasc Magn Reson 2012;14:58

33. Wilson M, O'Hanlon R, Prasad S, et al. Diverse patterns of myocardial fibrosis in lifelong, veteran endurance athletes. J Appl Physiol 2011;110:1622-6.

34. La Gerche A, Burns AT, Mooney DJ, et al. Exercise-induced right ventricular dysfunction and structural remodelling in endurance athletes. Eur Heart J 2012;33:998-1006. 